\title{
Erratum to: Mössbauer spectra of iron-doped titanium dioxide fine particles prepared by a soft chemical solution method
}

\author{
Junhu Wang • Yoichi Sakai
}

Published online: 23 January 2013

(C) Springer Science+Business Media Dordrecht 2013

\section{Erratum to: Hyperfine Interact DOI 10.1007/s10751-012-0722-4}

The authors would like to add the below acknowledgment to their article.

Acknowledgements Financial support obtained from the Chinese Academy of Sciences for "100 Talents" Project, the National Natural Science foundation of China (No. 11079036) and the Natural Science Foundation of Liaoning Province (No. 20092173) is greatly acknowledged.

The online version of the original article can be found at http://dx.doi.org/10.1007/s10751-012-0722-4.

J. Wang

Dalian Institute of Chemical Physics, Chinese Academy of Science,

Dalian 116023, China

Y. Sakai $(\bowtie)$

Daido University, Nagoya 457-8530, Japan

e-mail: yocsakai@daido-it.ac.jp 